\title{
Insurgent Attitude of Jammu and Kashmir State
}

\author{
Mudasir Hamid \\ Research Scholar, Jiwaji University, Gwalior (MP), India
}

\begin{abstract}
The frame of mind of Jammu And Kashmir State stays extremist. This paper is about the extremist clothing of J\&K state from most recent three decades which maybe upsets and bothers the political situation of entire Jammu and Kashmir State. The insurgency in Jammu and Kashmir is an inner conflict between Kashmiri guerillas, here and there known as "ultras" (fanatics), and the Government of India. A portion of the ultras support Kashmiri increase to Pakistan, while others look for Kashmir's finished autonomy. Insurgency drives country back advance who never create political, monetary and ethnic abilities for its open when all is said in done.
\end{abstract}

Keywords: Insurgency, Political Rights, India, Pakistan, Jammu and Kashmir, Indian Government

\section{Introduction}

The insurgency in Jammu and Kashmir is an inward conflict between Kashmiri agitators, at times known as "ultras" (radicals), and the Government of India. A portion of the ultras support Kashmiri promotion to Pakistan, while others look for Kashmir's finished freedom. Since 2002, engagements with the nearby agitators have established the primary conflict in the Kashmir region. The foundations of the conflict between the Kashmiri extremists and the Indian Government are fixing to an argument about neighborhood self-sufficiency. Majority rule advancement was restricted in Kashmir until the late 1970s and by 1988 a significant number of the vote based changes given by the Indian Government had been turned around and peaceful channels for communicating discontent were constrained and caused an emotional increment in help for guerillas supporting savage withdrawal from India. In 1987, a debated State decision made an impetus for the insurgency when it brought about a portion of the state's administrative gathering individuals shaping outfitted extremist gatherings. In July 1988 a progression of showings, strikes and assaults on the Indian Government started the Kashmir Insurgency which amid the 1990s swelled into the most critical inner security issue in India. A large number of individuals have kicked the bucket amid battling among guerillas and the legislature just as a great many regular people who have passed on because of being focused by the different equipped groups. The Inter-Services Intelligence of Pakistan has been blamed by India for supporting and preparing mujahedeen to battle in Jammu and Kashmir. As per official figures discharged in Jammu and Kashmir gathering, there were 3,400 vanishing cases and the conflict has left in excess of 47,000 individuals dead starting at July 2009. However, the quantity of insurgency-related passing in the state has fallen strongly since the beginning of a moderate moving harmony process among India and Pakistan. After 1947 from British principle India and Pakistan battled a war over the august province of Kashmir. Toward the finish of the war India at long last controlled the most significant parts of Kashmir. The insurgency in Jammu and Kashmir State has existed in different structures .Due to this individuals status with all public activity is purposely getting change. The essence of society are disjoining starting with one public activity then onto the next odd public activity. Insurgency maybe, more extensive conflict among
India and Pakistan over Kashmir. A great many lives have been lost since 1989 because of the escalation of both the insurgency and battle against it. The conventional culture of society is no uncertainty getting harm. The state is utilizing solid direction over the uprising issues. The two India and Pakistan reinforce their fringe areas however loosing the genuine social structure and its working. The terrible substance of insurgency as far as a wide spread furnished insurgency began in Kashmir with the debated 1987 race with a few components from the states get together shaping aggressors' wings which went about as an impetus for the rise of equipped insurgency in the region. It is even in news that the Inter-Service Intelligence (ISI) of Pakistan has been denounced by Indian by supporting and preparing Mujahedeen to battle in $\mathrm{J} \& \mathrm{~K}$. As indicated by authority figure discharged in $\mathrm{J} \& \mathrm{~K}$ gathering, there were 34,000 vanishing cases and the conflict has left in excess of 47,000 individuals dead as July 2009.

Be that as it may, the quantity of insurgency related passing in the state have fallen pointedly since the beginning of the moderate moving harmony process among India and Pakistan. The procedure of insurgency prompts the separation of the network starting with one region then onto the next. "Kashmiri Pundits" of Kashmir submerged from Kashmir to another spots of India. The insurgency development transforms into the development of individuals where social, political and even religious obstruction get advanced and state lost its command over the uprising Kashmir issue. Because of this both the networks of J\&K seriously faces the outcomes of insurgency and their disengagement of culture, custom, craftsmanship has turned into the exploitation of insurgence. According to K.P.S.Gill, among the most casualties of this conflict are the Kashmiri pundits, descendent of Hindu clerics and among the first occupants of the Radical Attitude of Jammu and Kashmir State Kashmir valley, with a recorder history of more than 5,000 years .throughout the centuries, this network has been indispensable not exclusively to social and scholarly existence of the general population of this region, however the rampart of its organization and monetary improvement too. Candid Pallove presented an unrest in the U.S House of delegates censuring the human rights infringement against the Kashmiri Pundits, Hindu occupants of the Kashmir valley, in the course of recent years. Pallove, who established the congressional council on India and India 
Americans, and seats the gathering Kashmir Task Force, acquainted the goals with desire the administration of India and state administration of $\mathrm{J} \& \mathrm{~K}$ to work with the pundit network to locate a quiet, evenhanded answer for the conflict presently occurring in the Kashmir valley. Since around 2000, the insurgency has turned out to be far less brutal and has rather gone up against type of challenges and walks. Certain gatherings have additionally decided to set down their arms and search for a serene goals to the conflicts. The distinctive extremist gatherings have diverse points in Kashmir. A few needs total freedom from the two India and Pakistan and still others need more noteworthy selfsufficiency from the legislature. An overview from that 43 $\%$ in Jammu and Kashmir would support freedom with help for the freedom development and unevenly disseminated over the region. Alongside rank, religious and semantic generalizations, there exist numerous other stereotyped pictures in our nation. Such picture is about our childhood. By making radical air in the express, the young moves toward becoming mental and physical injured individual and with the progression of time it turns out to be such picture in which youth are aggressor, uprisings, progressive, silly and disorderly. The facts demonstrate that adolescent are helpless against outside impact what's more, emulate others however this doesn't imply that the adolescent just have faith in pulverization, slaughtering, assault and fear based oppression. At the point when there is an all out dissatisfaction in the public arena with the current social structures and establishments, with the logical inconsistencies in the social framework, with the legislative issues and government officials, with the choices and leaders and at the point when everyone is aware of the falling principles in varying backgrounds, social segregation ,winning debasement, and the look for the brisk financial increases through ill-conceived implies, for what reason should the adolescent alone be relied upon to adjust to customary good qualities and grand beliefs ? How might they admire self-announced political, religious and social pioneers for motivation? It is intelligent to comprehend when there is a resistance disposition in the express; the adolescent transforms into distress and receives the method for settle down the unrest or disturbance. Youth figured it out the exasperates condition and they get disappoint in a network or a general public as the outcome youth end up fierce. The job of youth in fomentations and unrest like the activists unsettling for khalistan in Punjab and for an autonomous Kashmir in Jammu and Kashmir and inborn interest for a Jharkhand state in Bihar have likewise to be clarified as far as the disappointments of the young in the separate states. In Kashmir, the genuine power currently rests with the young fellows. Numerous people captured by the police for getting preparing in Pakistan are youthful people in the 18-25 age gatherings. A great deal of Kashmiris requesting autonomy are furious young fellows, who have sworn retribution.

\section{Reasons For Insurgency}

\section{Humanitarian abuses}

Some investigators have recommended that the quantity of Indian troops in Jammu and Kashmir is near 600,000 in spite of the fact that gauges shift and the Indian government declines to discharge official figures. These troops have occupied with across the board humanitarian abuses and have occupied with extrajudicial killings. In October 2010, Army Chief Gen VK Singh expressed in a meeting that over $95 \%$ of the charges of human rights infringement ended up being false and had obviously been leveled with the "ulterior rationale of defaming the equipped powers". Giving subtleties, he said 988 claims against the Army work force in Jammu and Kashmir were gotten since 1994. Out of these 965 cases were explored and 940 were discovered false, representing 95.2 percent. Military powers in Jammu and Kashmir work under crisis powers allowed to them by the focal government. These forces enable the military to reduce common freedoms, making further help for the insurgency. The guerillas have additionally manhandled human rights, taking part in what some have called an ethnic purifying by killing Kashmiri Pundits from the valley of Kashmir. The administration's failure to ensure the general population from the two its very own troops and the insurgency has additionally dissolved help for the legislature. Six Indian warriors, including two officers, were because of face a court military over extrajudicial killings.

ISI's role: The Pakistani Inter-Services Intelligence has purportedly energized and supported the Kashmir freedom development through an insurgency because of its question on the authenticity of Indian principle in Kashmir, with the insurgency as a simple method to keep Indian troops occupied and cause universal judgment of India.

Political rights: The insurgency was started by the apparatus of state races in 1987. This has added to hostile to government sentiment. A government report found that practically $50 \%$ of all Kashmiri Panchayat Raj positions were empty and recommended that the purpose behind this was the destabilizing impact of the conflict. The Panchayat Raj is an arrangement of chosen town level administration made by the 73 rd amendment to the Indian constitution. The report additionally noticed that their capacity to successfully administer was "injured." Radical Attitude of Jammu and Kashmir State There have been a few signs as of late that the Indian government has started to take Kashmiri political perspectives all the more truly, particularly those communicated through races. Amid the Jammu and Kashmir state get together races, 2008 the national decision party framed an alliance with the gathering that won the most votes so as to "respect the command" of the decision despite the fact that it was in opposition to their prompt interests.

Mujahedeen influence: After the intrusion of Afghanistan by the Soviet Union, Mujahedeen contenders, with the help of Pakistan, gradually invaded Kashmir with the objective of spreading an extreme Islamist belief system.

Religion: Jammu and Kashmir is the main Muslim dominant part state in Hindu-greater part India. Indian-American columnist Asra Nomani states that while India itself is a common state, Muslims are politically, socially and financially minimized when contrasted with Hindus in India all in all. The Government's choice to exchange 99 sections of land of timberland land to a Hindu association set this inclination and prompted one of the biggest dissent arouses in Jammu and Kashmir.

\section{Volume 8 Issue 2, February 2019 www.ijsr.net}


Other reasons: The Indian National Census demonstrates that Kashmir falls behind other states in generally socio development markers, for example, proficiency rates and has curiously abnormal amounts of joblessness. This contributes to against government conclusion. Other reasons: The Indian National Census demonstrates that Kashmir falls behind other states in generally socio development markers, for example, proficiency rates and has curiously abnormal amounts of joblessness. This contributes to against government conclusion.

\section{References}

[1] Ganguly, Sumit; Paul Kapur (7 August 2012). India, Pakistan, and the Bomb: Debating Nuclear Stability in South Asia. Columbia University Press. pp. 27-28. ISBN 978-0231143752.

[2] Multiple sources for the number of Indian counterinsurgency troops in the region.

[3] "India weighs troop reduction in quieter Kashmir". The Christian Science Monitor. April 2, 2007. Retrieved April 6, 2013.

[4] "Five CRPF officers dead in suicide attack as fidayeen extremists disguised as cricket players turn grenade launchers on Srinagar school". Daily Mail. 14 March 2013. Retrieved 31 March 2013.

[5] "After CM, Army voices concern". Greater Kashmir. 14 June 2013. Retrieved 14 June2013.800 Militants Active in Kashmir: Army

[6] "India revises Kashmir death toll to 47,000".Hindustan Times. 21 November 2008. Retrieved 2012-1109."Facts on Kashmiri Terrorism".

[7] "Kashmir Death Toll Hits 1,980 in 2003". The Washington Post. 21 November 2003.

[8] "India revises Kashmir death toll to 47,000". Reuters. 21 November 2008.

[9] "Kashmir fighting death toll hits 19". CNN. 23 March 2009. Retrieved 5 May 2010.

[10] "India revises Kashmir death toll to 47,000". Hindustan Times. Reuters. 21 November 2008.

[11] Agencies (6 April 2012). "Attempts will be made to push ultras across LoC:Army". Indian Express. Archived from the original on 7 January 2014.

[12] Press Trust of India (PTI) (7 January 2014). "Militants, Army troopers exchange fire in Pulwama, none hurt".Times of India. Archived from the original on 7 January2014.

[13] Social Studies S5 Ab. Pearson Education. p. 70.ISBN 978-981-4114-72-1.

[14] Uppsala Conflict Data Program Conflict Encyclopedia, Conflict Summary, Conflict name: India: Kashmir, Type of incompatibility: Territory, Interstate/intrastate dimension: Intrastate, Conflict status: Ongoing, Date of first stated goals of incompatibility: 29 May 1977, viewed 2013-0529,http://www.ucdp.uu.se/gpdatabase/gpcountry.php?i $\mathrm{d}=74 \&$ regionSelect=6-Central_and_Southern_Asia\#.

[15] Uppsala Conflict Data Program Conflict Encyclopedia, Conflict Summary, Conflict name: India: Kashmir, "Roots of Conflict and the emergence of Kashmir Insurgents, viewed 2013-0529,http://www.ucdp.uu.se/gpdatabase/gpcountry.php?i $\mathrm{d}=74$ \& regionSelect=6-Central_and_Southern_Asia\#
[16] "Elections in Kashmir".Kashmirlibrary.org. Retrieved 2013-01-06.

[17] "India Pakistan | Timeline".BBC News. Retrieved 2010-02-02.

[18] "Kashmir: A History Littered With Rigged Elections (by Mushtaq A. Jeelani) - Media Monitors Network". Mediamonitors.net. Retrieved 2010-02-02.

[19] Hussain, Altaf (14 September 2002). "South Asia Kashmir's flawed elections". BBC News. Retrieved 2010-02-02.

[20] Uppsala Conflict Data Program Conflict Encyclopedia, Conflict Summary, India: Kashmir (entire conflict), Fatality estimates, viewed 2013-0529,http://www.ucdp.uu.se/gpdatabase/gpcountry.php?i $\mathrm{d}=74 \&$ regionSelect=6-Central_and_Southern_Asia\# .

[21] Uppsala Conflict Data Program Conflict Encyclopedia, India One-sided violence, Government of India civilians, Kashmir insurgents - civilians, Lashkar-eTaiba - Civilians, viewed on 2012-0529,http://www.ucdp.uu.se/gpdatabase/gpcountry.php?i $\mathrm{d}=74 \&$ regionSelect=6-Central_and_Southern_Asia\# .

[22] Pakistan's shadowy secret service - BBC News.

[23] Nato's top brass accuse Pakistan over Taliban aid Telegraph .

[24] At Border, Signs of Pakistani Role in Taliban Surge New York Times .

[25] A NATION CHALlENGED: THE SUSPECTS; Death of Reporter Puts Focus On Pakistan Intelligence Unit - New York Times .

[26] Indian officials say 3,400 missing in held Kashmir (August 18, 2009; AFP) Bose, Sumantra.Kashmir: Roots of Conflict, Paths to Peace. Harvard, 2005.

[27] Swami, Praveen.India, Pakistan and the Secret Jihad. 2006. Mohd, Abbas Wani (2014). "Beginning of Terrorism in Jammu Kashmir". IndianStreams Research Journal(Laxmi Book Publication). ISSN 2230-7850. Altaf, Hussein.] "Kashmir's Flawed Elections".

[28] Fatalities in Terrorist Violence 1988 - 2014 in Jammu \& Kashmir, South Asian Terrorism, SATP (2014) Jamar, Arif.The untold story of Jihad in Kashmir. 2009.

[29] Hasan, Syed Shoaib. "Why Pakistan is boosting Kashmir militants" Khan, Aamer Ahmed."Pakistan: Where have the militants gone?"

[30] Tucker, Spencer C. (2013). Encyclopedia of Insurgency and Counterinsurgency A New Era of Modern Warfare. Santa Barbara, California: ABCCLIO,LLC. ISBN 978-1-61069-279-3.

[31] Stephens, Bret. "The most difficult job in the world" Cole, Juan. "Does Obama understand his biggest foreign-policy challenge? 